\title{
On the Practical Teaching Reform of Public Administration for the Cultivation of the "Internet + Industry Administration" Ability
}

\author{
Yujuan Chen, Jinyu Liu*
}

\author{
School of Politics and Administration, South China Normal University, Guangzhou 510631, China \\ *Corresponding author
}

\begin{abstract}
The practical teaching of political and administrative majors is facing problems of transformation. First, we should conform to the developing trend of the "Internet +" era, and cultivate professionals with the "Internet +" spirits and thoughts, and master the "Internet + Government administration" skills. Second, we should start from the actual needs of society and students, vigorously dig public resources in the field of industry administration, and broaden the width of training. To this end, this article focuses on the three dimensions of the analytical ablility of industry policies and regulations, the ability to grasp the frontier dynamics of industry management practices, and the application ability to apply information technology to big data analysis and application, to emphasis on the cultivatation of "Internet + Industry administration" ability of the students, thereby assist to the smooth transition of practical teaching in political and administrative majors, and to improve the professional ability and social adaptability of the students.
\end{abstract}

Keywords: Public administration, Practical teaching, "Internet + Industry administration"

\section{论面向“互联网+行业行政”能力培育的公共行政学实践 教学改革}

陈钰娟，刘劲宇*

华南师范大学政治与公共管理学院, 广州市, 中国

*通讯作者

中文摘要

政行专业的实践教学面临着转型问题。一是要顺应 “互联网+” 时代发展的潮流，培育具有 “互联网 +” 精神与思维, 掌握 “互联网+政务” 技能的专业人才。二是要从社会与学生的实际需要出发, 大力 挖掘行业行政领域的公共资源, 拓宽培养口径。为此, 本文着重从行业政策与法规的分析能力、行业 管理实践前沿动态的把握能力以及面向大数据分析与应用的信息技术应用能力三个维度入手强调对学 生进行 “互联网+行业行政” 能力的培育, 从而助力政行专业实践教学顺利转型, 提升学生们的专业 能力与社会适应能力。

关键词: 公共行政学; 实践教学; “互联网+行业行政” 


\section{1. 引言}

进入新世纪以来, 我国已有超过一百所本科院校开 办或曾经开办过政治学与行政学专业 (以下简称 “政行 专业”), 向各级各类公共部门输送了大量的专业人才, 较好地实现了开办这一专业的初衷, 也提升了自身的认 可度与实力。但随着 “双一流” 计划的推行, 以及国家 “互联网+”战略的深入实施, 政行专业的实践教学面 临着重大转型问题。如何结合 “互联网+” 时代的要求, 尽快从传统政务模式向 “互联网+政务” 转型升级, 从 而全面提升大学生 “互联网+” 应用能力, 成为了时代 性的新问题。这不仅要求我们加强理论思维训练, 以进 一步提升学生们对 “互联网+政务” 精神与理念的把握 能力, 更要求我们创新实践教学模式, 从而帮助学生们 更好地适应与掌握 “互联网+政务” 环境下管理作业的 基本思路、方法与技能。

但就现实而言, 政行专业面临着两大难题。一是专 业定位与社会期望之间存在落差。从社会期望来说, 不 少家长、学生是冲着 “培养公务员” 这一 (就业) 目标 而来的。然而, 从专业定位来说, 公共行政学的教育教 学在整体上仍侧重于专业自身发展的逻辑, 即以理论研 习为主导, 为了在 “专业丛林” 中获得普遍认可与更高 的地位, 而以培养高级理论型人才为其内在目的。因此, 在政行专业内部普遍存在着 “政治学强, 行政学弱” 现 象。这是第二个问题。由此, 更导致了理论教学重于实 践教学, 实践教学重点与方向不明确等问题。

随着 “互联网+”时代的来临, 蕴含于 “互联网+” 理念中的智慧正深刻变革着传统政务管理模式。具体来 说表现在以下三个方面: 一是以 “APP+小程序” 为代表 的移动互联网应用的技术门槛越来越低, 新一代大学生 的IT应用能力也有了显著提高, 这使得公共行政学实践 教学领域对信息技术应用的基础教学压力大幅度降低, 从而可以将教学重心转向管理实务领域; 二是一场以政 务大数据应用、政务流程再造为特征的 “互联网 + 政 务” 改革正在全国范围展开, 这使得公共行政学尘须更 加重视数据分析、流程再造等管理思想、方法与技术的 实践教学, 而以现代管理的 “中国方案” 为实践的具体 对象; 三是以 “跨界” 为显著特征的 “互联网+” 使得 公共行政学必须不断扩张其关注领域, 也就是说应当去 关照公司企业、社会组织等一切涉及公共领域的行政范 畴及其相应的实践领域, 从而适应当代社会对公共行政 学提出的新要求。

因此, 我们认为政行专业的建设与发展应以此为契 机, 以 “互联网+行业行政” 能力培育为新时代实践教 学的新目标, 以 “小课题研究” 为抓手, 以自主研习为 主要形式, 带动学生掌握更多政治学、行政学先进的思 想理论与通用性的技能, 从而进一步处理好理论教学与 实践教学的关系。

\section{2. 公共行政学实践教学视域中的 “互联网 + 行 业行政”能力}

所谓 “行业” 是指从事国民经济中同性质的生产、 服务或其他社会经济活动的经营单位和个体构成的组 织结构体系。因此, 行业行政泛指运行在这些组织中的 管理与服务事务与事项, 以及带有行业特征的各种计 划、组织、指挥、控制、协调、监督等活动。行业行政 一般包含两个方面的内容, 一是各行各业共通的行政事 务及其处理规则, 如公文管理、会议管理、人力资源管 理、资产管理等等。二是具有行业特性的管理实务，例 如, 教育行业人力资源管理必然涉及大量和教师与学 生、教育与教学相关的管理与服务事务, 其资产管理必 然涉及实验室、实验器材等方面的内容, 教育行业的公 文也必然会运用到大量的行业术语、专业名词等。由此 可见, 行业行政蕴含着丰富的教学与科研资源, 是公共 行政学开展实践教学的必然场域。

在我国, 随着社会主义市场经济体制的不断发展与 完善, 行业行政所涉及的领域越来越广泛, 对具有公共 行政学基础知识与专业技能的 “通才” 需求也越来越 高。这主要表现在以下几个方面: 首先, 作为一个传统 的中央行政大国，我国的政府在国民经济、文化与社会 领域起着关键性的枢纽作用。因此, 任何一个组织都要 懂得如何与政府打交道, 需要把握好执政党的治理理念 与经济社会的发展趋势, 从而保持正确的方向, 维持自 身的健康发展。其次, 进入新时代, 我国政府管理正面 临深刻的变革。随着 “放管服”、“互联网+政务服务” 等改革的深入推行, 任何一个组织都需要领会好公共政 策的导向，从而把握住发展的先机。第三，随着 “互联 网+” 的发展, 行业之间的边界越来越模糊, 融合发展 与创新成为了我们这个时代的主题。现代政府治理也要 求我们不断打破学科边界, 通过借鉴与融合其它领域的 知识、技术与方法, 来实现自身的创新与发展。因此,

“互联网+行业行政” 是公共行政学尘须高度关注的领 域。

我们也注意到, 在现有的公共行政学教学体系中较 少开设行业行政的专门课程, 但行政学相关课题研究、 实践教学乃至学生就业, 不仅需要结合特定的行业领域 来展开, 更会涉及到诸多 “跨行业” 领域的事务。因此, 我们认为公共行政学的实践教学, 既要积极向行业行政 领域拓展, 更要与 “互联网+” 紧密结合起来, 实现理 论研究的对象、过程、成果与实践教学的目标、导向等 要素的深度融合, 从而全面提升公共行政学教学质量与 科研水平。

\section{3. “互联网+行业行政” 能力的维度}

从公共行政学的视角看, 所谓 “互联网+行业行政” 能力就是指以行政学专业知识为基础, 以现代信息技术 应用为辅助, 引导学生通过自主学习而将个人兴趣与专 业方向结合起来, 将专业知识与行业实践结合起来的一 种综合研习能力。在实践教学中培育当代大学生的 “互 
联网+行业行政”能力，应注重培养他们对行业政策法 规的分析能力、行业管理实践前沿动态的把握能力以及 面向大数据分析与应用的信息技术应用能力。

\section{1. 行业政策与法规的分析能力}

当代中国是一个注重法治，以“依法治国” 为本的 国家。从国家到地方各种政策、法律、规章与标准，既 规范着人们的日常活动, 也规定着各级各类组织的日常 管理与运行活动。当然, 尚处于转型期间的我国在法制 与规范体系方面仍有许多需要完善之处。这就使得公共 行政学必须关照国家法治建设与发展问题。

首先, 这需要我们从行政科学的视角去分析、研究 这些与行业行政密切相关的政策、法律、规章与标准, 领会它们的精神，分析它们对行政过程及其结果的影 响。因为科学准确的分析为我们推动行业行政的实践发 展提供了理论前提和指引方向。其次, 这需要我们将纯 粹的学科视角与行业视角结合起来, 通过对行业实践的 分析与研究, 为国家法治建设、体制改革等公共领域的 事务提出有建设性的意见和建议。我们相信 “从学科到 行业” 的视角切换过程, 就是一个从理论到实践的过 程, 也是一个 “跨界融合” 过程。因此, 培育大学生的 “互联网+行业行政” 能力, 首先就是要提升他们对行 业政策与法规的分析能力。

\section{2. 行业管理实践前沿动态的把握能力}

所谓行业管理实践是指从事生产经营活动的单位、 组织根据行业发展方向和目标对行业进行一系列规划、 协调、指导活动的总称。而行业管理实践前沿动态便是 指在管理实践中依托新理念或新技术而进行的创新型 改革探索活动。

改革开放以来, 我国的公共行政学大致历经了一个 “重建一复兴” 的过程。所谓重建就是在 “拨乱反正” 的基础上, 重新建立起一套符合中国特色社会主义建设 需要的公共行政学学说体系, 理论探索是这一时期的主 要任务。为此, 我们借鉴了大量西方政治学、行政学理 论与学说, 基本恢复了学科理论体系。进入新世纪尤其 是加入WTO以来, 我国的各行各业在与世界接轨的同时, 也开始注意理论的本土化问题, 注重在实践中形成中国 特色的 “解决方案” 。例如, 随着国家网络强国战略与 “互联网+” 行动计划的施行, 行业领域的业务流程再 造终于从纸面上的理论走进了实践探索。其中, 最引人 瞩目的莫过于公共部门的政务流程再造。从2013年的 “五规合一”到2014年的 “多规合一” 试点工作的开 展, 我们可以看到改革的力度正在不断加大。而如今, 许多地区也正在以 “多规合一” 改革为推手, 大力推行 政务流程再造。例如, 2020年2月上海市提出要结合前 期 100项业务流程优化再造事项试点的情况, 全面推进 以企业和群众高效办成 “一件事” 为目标的政务流程 革命性再造。
而这一改革必将深刻地影响到政民关系、政企关 系, 而为新时代的大学生营造更为宽松的发展与创新环 境。因此, 大学生对行业管理实践前沿动态的把握能力, 既是专业自身发展的需要, 也是社会的需求。这一能力 的培养并非靠教师单向性地向学生进行灌输, 而是应以 自主研习为主要形式, 逐步培养公共行政学的学生形成 对行业管理实践的 “敏感性” , 能主动去探索、研究和 把握其前沿发展趋势。在这一过程中, 学生不仅能更明 确实践变革背后的 “互联网+政务服务”理念，对旧有 的行业行政流程进行理论上的反思，更能以前沿改革的 发展趋势为导向, 为其流程的优化提出建设性意见, 切 实推动实践上的进步。

\section{3. 面向大数据分析与应用的信息技术应用 能力}

大数据有 “体量之大”与 “格局之大” 的双重含 义。所谓体量之大, 就是指信息网络兴起以来, 存储与 运行于各类信息系统之上的海量数据。而所谓格局之 大, 主要指透过这些海量数据所能反映出的世界图景与 发展趋势。可以说, “互联网 + ” 时代的到来使得大数 据分析与应用成为任何一名当代大学生都应掌握的基 本能力。而对于公共行政学来说, 更要从 “格局之大” 的高度去领会大数据的影响与发展前景, 引入更多的公 共资源来丰富与改善我们的教学手段与内容, 从而不断 优化实践教学机制。

由于大数据在 “互联网+” 时代的当下发挥着重要 作用, 党的十八届五中全会公报提出要实施 “国家大数 据战略” ，旨在全面推进我国大数据发展和应用，加快 建设数据强国，推动数据资源开放共享。在政府的率先 示范下, 社会公共领域的行政范畴和实践领域亦掀起了 业务流程管理信息化、数据化以及数据的公开与共享浪 潮。这于行业内部和行业之间而言，打通了 “数据孤 岛”，顺应了“互联网+”带来的行业交叉发展趋势， 使其得以优化行政业务流程; 而于实践教学而言, 其提 供了 “小课题研究” 的实际案例, 使得学生能够根据自 身兴趣, 运用大数据分析特定行业的业务流程, 再结合 管理信息化、行业行政等方面的理论, 提出系统改进的 意见和建议。因此, 面向大数据分析带来的行业行政流 程数据化, 通过信息技术运用能力的培养带动学生掌握 更多通用性管理思想与技能，培养 “互联网+” 精神与 实践能力的新时代人才是当代社会对公共行政学发展 的迫切诉求。

\section{4. 提升 “互联网+行业行政” 能力的路径}

进入新世纪以来, 我国公共行政学的建设与发展是 以政治学与行政学、行政管理等相关专业的广泛开办为 显著特征的。随着人才培养规模的急剧扩容, 社会对人 才质量的要求也越来越高。这就使得公共行政学必须注 重实践教学, 通过转变教学理念、拓宽培养口径、创新 
教学模式等方式，面向 “互联网+行业行政”培育出更 多、更高质量的专业人才。

\section{1. 转变教学理念}

无论是国家政策层面还是社会公共领域的实践需 要, 都对公共行政学的教学改革和人才培养模式提出了 新的要求。而改革教学模式的前提是要实现教学理念的 转变, 这要求我们要摒弃 “重理论、轻实践” 的传统教 学理念, 科学把握理论与实践在公共行政学教学中的辩 证关系。政行专业既非纯理论学科, 也不能单独采取实 践教学, 而是应该将两者有机结合起来, 融为一体。在 学生已经牢固掌握了公共行政专业理论知识的基础上, 以行业需求为导向, 以互联网技术为载体, 着力培养学 生的行政实践技能, 最大程度避免教学内容与就业需要 间的脱节。

\section{2. 拓宽培养口径}

“互联网+政务服务”改革的深入推进, 要求公共 行政学实践教学要面向更广阔的行业行政领域, 培养适 应 “互联网+政务服务” 的复合型人才。因此, 我们要 以 “互联网+” 和大数据的发展为契机, 以现代信息技 术运用能力为基础, 大力挖掘行业行政领域的公共资 源, 来拓宽对政行学生的培养口径。一方面, 既能培养 学生综合处理事务的能力, 又能对学生进行社会公共领 域具体行业行政能力的针对性训练, 从而提升学生对社 会的适应能力和就业竞争力。另一方面, 也能向行业领 域输送更对口、更优质的公共行政人才, 推动行业行政 的进一步发展。

\section{3. 创新教学方式}

“互联网+”时代的到来使得传统政务管理模式发 生深刻变革, 既为我们的实践教学改革提供了技术支 持, 使其具备现实可能性, 也对我们提出了新的要求, 尤其是在信息技术运用方面的实操能力。为此, 我们提 倡坚持学生在学习过程中的主体地位, 充分发挥其自觉 能动性, 以自主研习为主要形式, 通过 “小课题研究” 的实践教学模式来引导学生提升自身的专业能力与社 会适应能力。

\section{5. 总结}

面向 “互联网+”时代重构公共行政学实践教学体 系, 仍有许多内容需要不断充实与完善。但相信, 充分 运用 “互联网+” 理念, 不断优化学科专业资源、社会 资源与互联网资源的连接点, 新一代公共行政学实践教 学体系定会紧跟时代步伐, 从而实现其应有的价值与作 用。

\section{致谢}

广东省高等教育教学研究和改革2017年项目《“互 联网+政务”: 创新公共行政实践人才培养模式的探索》

\section{REFERENCES}

[1] Zhang Ruixin, Li Bo, The Current Situation, Problems and Needed Support of Using Internet Platform for Teaching Activities-Taking the Department of Electronic Government Affairs of Jilin University as an Example. [J]. E-government, 2014(3):20-28.

[2] Gao Yanni, Research on Practical Teaching Reform of "E-Government" [J] Modern Educational Technology, 2008 (12): 104-106.

[3] Yu Yue, Yan Yan, Sun Jiushu.The purpose and requirements of the innovation of e-government practice teaching mode [J] e-government, 2014 (3): 16-19.

[4] Zuo Changsheng. The Practice of E-Government Teaching in the Experimental Course System of Public Management in Colleges and Universities [J]. E-Government Affairs, 2011 (2): 116-120.

[5] Chen Liming, Yu Qianchi. On the Management Process of Practical Teaching in Ideological and Political Theory Courses [J]. Culture and Education Materials, 2011 (26): 117-119.

[6] Wang Lei. Practical Research on Information Technology Precision Teaching Model under the Background of Big Data (Part One) [J]. China Information Technology Education, 2019 (24): 27-30.

[7] Sun Guangxia, "Interpretation and Analysis of the Limitations of Public Administration Practice Teaching Based on Reflexivity Theory" Journal of Beijing Institute of Electronic Technology 2016 No. 1 